\title{
Factors Influencing Organizational Commitment Among Male Nurses in Korea
}

\author{
Kwang-Min Choi a, Mi-Kyeong Jeon b,* \\ ${ }^{a}$ Department of Nursing, Daejeon Regional Trauma Center, Daejeon Eulji Medical Center, Daejeon, Korea \\ ${ }^{b}$ Department of Nursing, Changwon National University, Changwon, Korea
}

\section{Article history:}

Received: February 2, 2021

Revised: March 31, 2021

Accepted: April 16, 20201

\section{${ }^{*}$ Corresponding Author:}

Mi-Kyeong Jeon

Department of Nursing, Changwon National University, Changwon, Gyeongsangnam-do 51140 Korea

E-mail: mkjeon@changwon.ac.kr

ORCID

Kwang-Min Choi

https://orcid.org/0000-0001-8409-5614

Mi-Kyeong Jeon

https://orcid.org/0000-0001-6730-2423

\section{ABSTRACT}

Purpose: This study aimed to identify factors influencing organizational commitment among male nurses in Korea.

Methods: This study was conducted from July to September, 2018. Data were collected from 166 male nurses whom worked for more than 6 months in secondary or tertiary hospitals in Korea. The data were analyzed using descriptive statistics, t-test, analysis of variance (ANOVA), Pearson's correlation coefficient, and multiple regression.

Results: Organizational commitment showed significant differences in age $(t=-4.69, p<0.001)$, marital status $(t=-2.95, p=0.004)$, total nursing career $(F=4.91, p=0.003)$, total career in the present hospital $(\mathrm{F}=4.98, p=0.002)$, total career in the present department $(\mathrm{F}=5.47, p=0.001)$, affiliation in the hospital $(t=2.28, p=0.024)$ and annual average income $(t=-2.55, p=0.012)$. Organizational commitment correlated positively with gender role conflict $(r=0.28, p<0.001)$ and job satisfaction $(r=0.21, p=0.008)$. The major factors influencing organizational commitment were identified as gender role conflict $(B=0.11, p<0.001)$, job satisfaction $(B=0.29, p<0.001)$ and age ( $B$ $=4.77, p=0.018$, which explains $23 \%$ of the variance in organizational commitment.

Conclusion: The factors identified in this study which influenced organizational commitment in male nurses, could be used to assign nursing tasks and rotations. Interventional or education programs may be prepared to improve organizational commitment of male nurses.

Keywords: gender role, gender role conflict, job satisfaction, male nurses, organizational objectives

\section{Introduction}

Expertise in the nursing profession and a breakdown of stereotypes around nursing has led to increasing numbers of men choosing to become a nurse. The first male nurse in Korea began his career in 1962, and in 2020, the number of male nurses was 21,042 which accounted for $4.8 \%$ of the total number of nurses in Korea $(436,565)$ [1]. Male nurses in hospitals have typically been allocated to particular departments including the emergency rooms, intensive care units, and operating rooms in consideration of the work intensity, and without regard for their personal characteristics. With the increase in number of male nurses, more male nurses are being allocated to general wards, and their scope of activities in the clinical setting has become wider. This has brought about difficulties for male nurses because amongst other factors, the occupation of nursing is still regarded as a woman's job and the recognition of male nurses in the culture of the hospital is still low [2]. In clinical setting, they are regarded as "male" nurses rather than "nurses" [3].

Male nurses are typically assigned surgical assistant or physician assistant positions, rather than carrying out general tasks associated with working on a general ward. Consequently, their work authorization and limitation of liability are not clear and thus role conflicts are caused. This impacts negatively on their job satisfaction and organizational commitment [4]. 
As a result, many male nurses, although being satisfied with their occupation as a nurse, conclude that the organization is different from what they thought it was going to be [5]. Male nurses despite accumulating a considerable amount of clinical job experience, tend to move to a different organization. So, rather than working for a hospital, they work for the fire brigade, the health service, or a medical device company [6].

Organizational commitment, is a concept which reflects the psychological state of an individual towards an organization, and is the identification of oneself within the organization to which he or she belongs, or an expression of allegiance to it by internalizing the values of the organization [7]. In addition, it is the emotional affection towards the organization itself while fulfilling one's role to their best ability to achieve the goals and values of the organization [8].

In the present study (with the purpose of increasing organizational commitment of male nurses), the relevant factors were studied, and the effects of gender stereotype, gender role conflict, and job satisfaction were measured. This will provide fundamental data which may help in the diversification of the typical roles male nurses perform in hospitals so that the organization will value male nurses as a human resource.

\section{Materials and Methods}

\section{Study design, participants, and settings}

This study used a cross-sectional design, and the participants were male nurses who had worked for more than 6 months in a secondary or tertiary hospital in South Korea. Convenience sampling was employed to select 8 hospitals, all of which gave their consent to the survey. With the cooperation of the Korean mannurses association, participants received information from the 10 hospitals where male nurses frequently worked. The researcher directly explained the purpose of the study to the Korean mannurses association or the head of the nursing department at all 10 hospitals. Eight hospitals were selected to participate in the study, and each hospital decided and informed the number of participants. The questionnaire was contained in an individual envelope which was delivered to the participants, and after completion of the questionnaire, the questionnaire was sealed and collected. The required sample size was estimated using $G^{*}$ Power 3.1 [9]. With an input at 0.05 , a medium effect size of 0.15 , a power of 0.90 , and the number of predictors at 15 for a linear multiple regression analysis, the minimum sample size required for this study was 166. In consideration of a potential dropout rate of about $10 \%$, questionnaires were distributed to 185 male nurses. Unanswered questionnaires were excluded, leaving 166 questionnaires which were used as valid data in this study.
Data were collected during the period from July 11 to August 31, 2018.

Approval for conducting this study was obtained from the Institutional Review Board of Eulji University in Korea (no.: EUIRB2018-52).

\section{Measurements}

\subsection{Gender stereotype}

Gender stereotype was measured using the Gender Stereotype Inventory developed by Kim [10]. It contains 33 items, each of which is rated on a 5-point Likert scale ( $1=$ strongly disagree to $5=$ strongly agree). Higher scores represent a stronger belief in gender stereotypes. Kim [10] reported the internal consistency coefficient (Cronbach's $\alpha$ ) of this scale was 0.92 . In the current study it was 0.93 .

\subsection{Gender role conflict}

Gender role conflict was assessed using the Korean Male Gender Role Conflict Scale developed by Lee et al [11]. The scale comprises 37 items which are rated on a 6-point Likert scale, ranging from 1 (strongly disagree) to 6 (strongly agree), with higher scores indicating greater gender role conflict. Lee et al [11] reported the internal consistency coefficient (Cronbach's $\alpha$ ) of this scale was 0.90 . In the current study it was 0.93 .

\subsection{Job satisfaction}

The study applied the Korean version of the MINNESOTA Satisfaction Questionnaire, whose reliability and validity were verified after it was developed by Weiss et al [12] and translated to Korean for validation by Park [13]. The instrument consists of 3 subscales and 20 items. The items are rated on a 5-point Likert scale, ranging from 1 (strongly dissatisfied) to 5 (strongly satisfied), with higher scores indicating higher job satisfaction. Cronbach's $\alpha$ of this scale reported by Park [13] was 0.82 . In the current study it was 0.87 .

\subsection{Organizational commitment}

The questionnaire by Meyer et al [14] was used to assess male nurses' organizational commitment. This questionnaire consists of 15 items. Male nurses were rated on a 5-point Likert scale, from 1 (strongly disagree) to 5 (strongly agree), with higher scores denoting higher organizational commitment. Cronbach $\alpha$ of this scale was 0.84 [14]. In the present study it was 0.80 .

\section{Data analysis}

The data were collected and analyzed using SPSS for Windows Version 21.0 (IBM Corp., Armonk, NY, USA), and the normal distribution of the main variables was confirmed using the Kolmogorov-Smirnov test before analysis. The participants' general characteristics, gender stereotype, gender role conflict, job satisfaction, and organizational commitment were analyzed with descriptive statistics. Scale reliability was assessed using Cronbach $\alpha$. Differences in organizational commitment 
according to general characteristics were analyzed using the independent t-test, analysis of variance, and Scheffé's post hoc test. Correlation was computed using Pearson's correlation test. To explore factors which influenced organizational commitment, multiple regression was performed to determine which factors were relevant and how those factors influenced each factor.

\section{Results}

The general characteristics of participants are shown in Table 1. The mean age of the participants was $28.43( \pm 4.82)$ years. There were 138 participants (83.1\%) who were not married and 126 (75.9\%) who had graduated from university. Among the participants, 155 (93.4\%) had served in the military. There were 112 (67.5\%) participants who were employed in general hospitals. There were $73(44.0 \%)$ participants who worked at the hospitals located in metropolitan cities. The mean amount of time participants had invested in their nursing career so far was 42.70 ( \pm 50.55$)$ months. The mean amount of time spent working in the present hospital was $38.35( \pm 42.75)$ months. There were $45(27.1 \%)$ participants who were ICU nurses. The amount of time working in the present department was $31.60( \pm$ 33.06) months. There were 152 (91.6\%) participants who were in the nursing department. There were 112 (67.5\%) participants who were nursing staff. As for the type of duty, 96 (57.8\%) participants had fixed work, and 70 (42.2\%) participants had 3-shift work. There were 129 (77.7\%) participants who earned an annual average income of less than 46 million won (based on individual tax rates).

The participants' gender stereotype, gender role conflict, job satisfaction, and organizational commitment are shown by Table 2 . Organizational commitment had statistically significant differences with age $(t=-4.69, p<0.001)$, marital status $(t=-2.95, p=0.004)$, total nursing career $(\mathrm{F}=4.91$,

Table 1. Differences of organizational commitment according to general characteristics $(N=166)$.

\begin{tabular}{|c|c|c|c|c|c|}
\hline \multirow{2}{*}{ Characteristics } & \multirow{2}{*}{ Categories } & \multirow{2}{*}{$\begin{array}{c}N(\%) \\
\text { or } \mathrm{M} \pm \mathrm{SD}\end{array}$} & \multicolumn{3}{|c|}{ Organizational commitment } \\
\hline & & & $\mathrm{M} \pm \mathrm{SD}$ & $\mathrm{t} / \mathrm{F}$ & $\begin{array}{c}p \\
\text { (Scheffé) }\end{array}$ \\
\hline \multirow[t]{3}{*}{ Age (y) } & $\leq 30$ & $133(80.1)$ & $42.39 \pm 8.00$ & -4.69 & $<0.001$ \\
\hline & $>30$ & $33(19.9)$ & $49.52 \pm 7.01$ & & \\
\hline & & $28.43 \pm 4.82$ & & & \\
\hline \multirow[t]{2}{*}{ Marital status } & Single & $138(83.1)$ & $42.97 \pm 8.22$ & -2.95 & 0.004 \\
\hline & Married & $28(16.9)$ & $47.93 \pm 7.57$ & & \\
\hline \multirow[t]{3}{*}{ Level of education } & College & $35(21.1)$ & $45.67 \pm 8.88$ & 2.87 & 0.060 \\
\hline & University & $126(75.9)$ & $43.04 \pm 8.03$ & & \\
\hline & $\geq$ Master degree & $5(3.0)$ & $50.00 \pm 7.71$ & & \\
\hline \multirow[t]{2}{*}{ Military } & Finished & $155(93.4)$ & $43.95 \pm 8.17$ & 0.86 & 0.392 \\
\hline & Waived & $11(6.6)$ & $41.73 \pm 10.16$ & & \\
\hline \multirow[t]{2}{*}{ Hospital type } & $\begin{array}{l}\text { Advanced general } \\
\text { hospital }\end{array}$ & $54(32.5)$ & $45.45 \pm 8.13$ & 1.78 & 0.077 \\
\hline & General hospital & $112(67.5)$ & $43.01 \pm 8.30$ & & \\
\hline \multirow[t]{3}{*}{ Location } & Seoul special city & $32(19.3)$ & $45.31 \pm 7.34$ & 0.73 & 0.486 \\
\hline & Metropolitan city & $73(44.0)$ & $43.20 \pm 8.27$ & & \\
\hline & Province & $61(36.7)$ & $43.74 \pm 8.83$ & & \\
\hline \multirow{5}{*}{$\begin{array}{l}\text { Total nursing career } \\
\text { (mo) }\end{array}$} & $\leq 12(\mathrm{a})$ & $35(21.1)$ & $45.03 \pm 7.12$ & 4.91 & 0.003 \\
\hline & $12 \leq 36(b)$ & $74(44.6)$ & $41.52 \pm 7.88$ & & $(a, c, d>b)$ \\
\hline & $36 \leq 60(c)$ & $24(14.5)$ & $43.67 \pm 9.68$ & & \\
\hline & $\geq 61(\mathrm{~d})$ & 33 (19.9) & $47.73 \pm 7.92$ & & \\
\hline & & $42.70 \pm 50.55$ & & & \\
\hline
\end{tabular}


Table 1. (Continued).

\begin{tabular}{|c|c|c|c|c|c|}
\hline \multirow{2}{*}{ Characteristics } & \multirow{2}{*}{ Categories } & \multirow{2}{*}{$\begin{array}{c}N(\%) \\
\text { or } \mathrm{M} \pm \mathrm{SD}\end{array}$} & \multicolumn{3}{|c|}{ Organizational commitment } \\
\hline & & & $\mathrm{M} \pm \mathrm{SD}$ & $\mathrm{t} / \mathrm{F}$ & $\begin{array}{c}p \\
\text { (Scheffé) }\end{array}$ \\
\hline \multirow{5}{*}{$\begin{array}{l}\text { Total career in the } \\
\text { present hospital } \\
\text { (mo) }\end{array}$} & $\leq 12(\mathrm{a})$ & $39(23.5)$ & $44.00 \pm 8.04$ & 4.98 & 0.002 \\
\hline & $12 \leq 36(b)$ & $75(45.2)$ & $41.86 \pm 8.05$ & & $(a, c, d>b)$ \\
\hline & $36 \leq 60(c)$ & $24(14.5)$ & $43.84 \pm 8.53$ & & \\
\hline & $\geq 61(\mathrm{~d})$ & $28(16.9)$ & $48.71 \pm 7.41$ & & \\
\hline & & $38.35 \pm 42.75$ & & & \\
\hline \multirow{5}{*}{$\begin{array}{l}\text { Present working } \\
\text { department }\end{array}$} & General ward & $16(9.6)$ & $43.69 \pm 10.33$ & 1.11 & 0.353 \\
\hline & ER & $28(16.9)$ & $41.76 \pm 9.13$ & & \\
\hline & OR/REC & $44(26.5)$ & $45.00 \pm 7.61$ & & \\
\hline & ICU & $45(27.1)$ & $42.80 \pm 8.31$ & & \\
\hline & Other & $33(19.9)$ & $45.36 \pm 7.25$ & & \\
\hline \multirow{5}{*}{$\begin{array}{l}\text { Total career in the } \\
\text { present department } \\
(\mathrm{mo} ; n=165)\end{array}$} & $\leq 12(\mathrm{a})$ & $45(27.1)$ & $43.42 \pm 8.29$ & 5.47 & 0.001 \\
\hline & $12 \leq 36(b)$ & $77(46.4)$ & $41.99 \pm 7.79$ & & $(\mathrm{a}, \mathrm{c}, \mathrm{d}>\mathrm{b})$ \\
\hline & $36 \leq 60(c)$ & $23(13.9)$ & $45.57 \pm 8.81$ & & \\
\hline & $\geq 61(\mathrm{~d})$ & $20(12.0)$ & $49.80 \pm 7.12$ & & \\
\hline & & $31.60 \pm 33.06$ & & & \\
\hline \multirow{2}{*}{$\begin{array}{l}\text { Affiliation in the hospital } \\
(n=160)\end{array}$} & Nursing department & $152(91.6)$ & $44.07 \pm 8.23$ & 2.28 & 0.024 \\
\hline & Medical department & $8(4.8)$ & $37.25 \pm 8.48$ & & \\
\hline \multirow{3}{*}{$\begin{array}{l}\text { Task of job } \\
(n=156)\end{array}$} & Nursing staff & $112(67.5)$ & $43.64 \pm 8.58$ & 1.72 & 0.182 \\
\hline & Medical support staff & $41(24.7)$ & $44.17 \pm 7.77$ & & \\
\hline & Administrator & $3(1.8)$ & $52.67 \pm 7.37$ & & \\
\hline \multirow[t]{2}{*}{ Type of duty } & Fixed & $96(57.8)$ & $44.79 \pm 8.24$ & 1.30 & 0.194 \\
\hline & 3-shift & $70(42.2)$ & $43.09 \pm 8.32$ & & \\
\hline \multirow{2}{*}{$\begin{array}{l}\text { Annual average income } \\
\text { (thousand won) } \\
(n=156)\end{array}$} & $\leq 46,000$ & $129(77.7)$ & $43.00 \pm 8.23$ & -2.55 & 0.012 \\
\hline & $>46,000$ & $27(16.3)$ & $47.41 \pm 7.85$ & & \\
\hline
\end{tabular}

$\mathrm{ER}=$ emergency room; OR = operating room; REC = recovery room; ICU = intensive care unit.

Table 2. Correlation amongst gender stereotype, gender role conflict, job satisfaction, and organizational commitment $(N=166)$.

\begin{tabular}{|c|c|c|c|c|c|c|}
\hline Variables & $\begin{array}{c}\text { Average score } \\
\mathrm{M} \pm \mathrm{SD}\end{array}$ & $\begin{array}{c}\text { Total score } \\
\mathrm{M} \pm \mathrm{SD}\end{array}$ & $\begin{array}{c}\mathrm{X} 1 \\
\mathrm{r} \\
(p)\end{array}$ & $\begin{array}{c}\mathrm{X} 2 \\
\mathrm{r} \\
(p)\end{array}$ & $\begin{array}{c}\mathrm{X} 3 \\
\mathrm{r} \\
(p)\end{array}$ & $\begin{array}{c}\mathrm{X} 4 \\
\mathrm{r} \\
(p)\end{array}$ \\
\hline Gender stereotype (X1) & $2.30 \pm 0.50$ & $75.88 \pm 16.35$ & 1 & & & \\
\hline Gender role conflict (X2) & $3.03 \pm 0.61$ & $112.01 \pm 22.68$ & $\begin{array}{c}-0.32 \\
(<0.001)\end{array}$ & 1 & & \\
\hline Job satisfaction (X3) & $3.31 \pm 0.44$ & $66.12 \pm 8.77$ & $\begin{array}{c}0.27 \\
(<0.001)\end{array}$ & $\begin{array}{c}-0.31 \\
(<0.001)\end{array}$ & 1 & \\
\hline Organizational commitment (X4) & $2.92 \pm 0.55$ & $43.8 \pm 8.30$ & $\begin{array}{c}-0.05 \\
(0.565)\end{array}$ & $\begin{array}{c}0.28 \\
(<0.001)\end{array}$ & $\begin{array}{c}0.21 \\
(0.008)\end{array}$ & 1 \\
\hline
\end{tabular}


Table 3. Multiple regression of factors influencing organizational commitment $(N=166)$.

\begin{tabular}{|c|c|c|c|c|c|c|}
\hline & B & SE & ß & $t$ & $p$ & VIF \\
\hline Constant & 7.897 & 6.391 & & 1.236 & 0.218 & \\
\hline Gender role conflict & 0.111 & 0.028 & 0.304 & 3.913 & $<0.001$ & 1.296 \\
\hline Job satisfaction & 0.287 & 0.069 & 0.303 & 4.165 & $<0.001$ & 1.137 \\
\hline $\begin{array}{l}\text { Age } \\
\text { (ref: } \leq 30 \mathrm{y})\end{array}$ & 4.774 & 1.989 & 0.230 & 2.400 & 0.018 & 1.980 \\
\hline $\begin{array}{l}\text { Marital status } \\
\text { (ref: single) }\end{array}$ & 2.034 & 2.049 & 0.092 & 0.993 & 0.322 & 1.850 \\
\hline $\begin{array}{l}\text { Affiliation in the organization } \\
\text { (ref: medical department) }\end{array}$ & 3.454 & 2.107 & 0.116 & 1.639 & 0.103 & 1.078 \\
\hline $\begin{array}{l}\text { Annual average income } \\
\text { (ref: } \leq 46,000,000 \text { won) }\end{array}$ & 0.297 & 1.767 & 0.013 & 0.168 & 0.867 & 1.337 \\
\hline \multicolumn{7}{|c|}{$\begin{array}{c}\mathrm{R}^{2}=0.26, \text { Adjusted } \mathrm{R}^{2}=0.23, \mathrm{~F}=9.39, p<0.001 \\
D(d u)=2.09(1.81), \mathrm{Z}(p)=0.665(0.769), \mathrm{x}^{2}(p)=9.69(0.138)\end{array}$} \\
\hline
\end{tabular}

VIF = variance inflation factor.

$p=0.003)$, and total career in the present hospital $(\mathrm{F}=4.98, p$ $=0.002)$, total career in the present department $(\mathrm{F}=5.47, p<$ $0.001)$, affiliation in the hospital $(t=2.28, p=0.024)$, average annual income $(t=-2.55, p=0.012)$ (Table 1$)$. Organizational commitment has positively correlated with gender role conflict $(\mathrm{r}=0.28, p<0.001)$ and job satisfaction $(\mathrm{r}=0.21, p=0.008)$.

As a result of multiple regression analysis shown in Table 3 , gender role conflict ( $p<0.001)$, job satisfaction $(p<0.001)$, and age $>30$ years $(p=0.018)$ were influencing factors on organizational commitment. The explanatory power of these variables to explain the dependent variable was $23 \%$, and had an effect in the order of gender role conflict ( $\beta=0.304)$, job satisfaction $(~(=0.303)$, and age $>30$ years $(\beta=0.230)$. As a result of performing the normality test of the residuals to check the goodness-of-fit of the regression model, the Kolmogorov-Smirnov Z value was 0.665 ( $p=0.769$ ). As a result of performing the test for equal variance of the residuals, Breusch-Pagan value was 9.690 ( $p=0.138)$. Thus, the regression model was statistically appropriate.

\section{Discussion}

The present study was conducted to investigate the effects of gender stereotype, gender role conflict, and job satisfaction of male nurses on organizational commitment with the intension to provide fundamental data to improve organizational commitment. This may be in the form of improving the working environment in hospitals or developing an intervention program.
The average score for gender stereotypes was $2.30 \pm 0.50$ points out of 5 . This result was consistent with previous studies where gender stereotypes were higher in male nurses compared with female nurses $[15,16]$. The high score for male nurses regarding gender stereotype may reflect the conservative idea which is prevalent in Korean society, that men should have the patriarchal roles and take the lead in work [17]. Consequently, male nurses tend to consider nursing an inappropriate career and recognize the negativity around male nurses [18]. Therefore, to reduce the prevalence of gender stereotypes experienced by male nurses working in a clinical setting, there needs to be gender equality education.

The average gender role conflict score was $3.03 \pm 0.61$ points out of 6 . This score was similar to a previous study conducted with male nurses [19] but lower than the score reported in a study of the development of the male role conflict scale conducted by Lee et al [11]. The result of the current study is consistent with a previous report [20] that the gender role conflict score of men working in a women-centered organization, such as nursing or education, is lower than men working in a typical men-centered organization. This result may be understood in the context that male nurses selected their career choice after careful consideration [21].

The average job satisfaction score was $3.31 \pm 0.44$ points out of 5 . The score was lower than the score in previous studies conducted with male nurses $[2,22,23]$ and a previous study conducted with female nurses [24]. Due to the characteristics of the work, male nurses should continuously communicate and work with female nurses. This may present difficulties because societal pressure may cause male nurses to feel 
unsatisfied with their professional status in society [18].

The average organizational commitment score was 2.92 \pm 0.55 points out of 5 . The score was similar to the score in a previous study conducted with new employees in large companies [25] and lower than the score in a previous study conducted with female nurses [24]. In typical organizations, men's organization commitment is generally high, because the job and organizational structure are advantageous for males, and men usually have more opportunities for mutual exchange among the employers and employees. In the present study however, organizational commitment of the male nurses was lower than that of the female nurses, probably because organizational commitment was affected by the women-centered organization. Considering the demographical characteristics of the participants, organizational commitment was higher among those who were older and married, which is consistent with a relevant previous report [18]. Organizational commitment was significantly different depending on the total amount of time invested in their nursing career, the total career period in the present hospital, the total length of time of their careers in the present department, the affiliation to the hospital, and the annual average income. This finding was consistent with a previous report that organizational commitment was higher among those who have had a longer career and who are paid more $[18,26]$.

In this current study, the correlations among gender stereotype, gender role conflict, job satisfaction, and organizational commitment were investigated, and organizational commitment showed a significantly positive correlation with gender role conflict, and with job satisfaction. This finding was consistent with the previous studies conducted with nurses where a positive correlation was observed between organizational commitment and job satisfaction [27,28], but different from a previous study that reported a negative correlation [18]. This result was consistent with the previous studies where a positive correlation was determined between organizational commitment and the gender role conflict $[26,29]$

The regression model identified gender role conflict, job satisfaction, and age as the factors which influenced organizational commitment. Organizational commitment was higher among the nurses aged $>30$ years, a higher gender role conflict score and a job satisfaction score. This may suggest that when male nurses become satisfied with their job and progress in their profession, they become committed to the organization despite nursing being classified as a woman's job in Korean society. Satisfaction with the job inspires voluntary participation and creativity, creating a positive effect upon collaborative work to accomplish the goals of the organization [28]. In addition, with increasing age the chances for promotion are elevated and a career has longevity which enables people to have a strong positive outlook upon the goals and values of the organization. Likewise, organizational commitment of the male nurses increased with age and with increased responsibilities in their roles as experienced nurses in the hospitals or nursing organizations.

As described above, the factors which influence organizational commitment in male nurses should be taken into consideration when preparing suitable policies for enhancing organizational commitment. Although increased expertise of nursing may encourage men into the profession, male nurses still undergo difficulties due to the prejudice and social stereotypes around nursing being a woman's job. Therefore, a social understanding of the nursing profession should be challenged to create change, and consideration should be given to male nurses in the allocation of jobs in various departments of nursing in order to increase organizational commitment in male nurses. Based on the results of this study, it is necessary to develop and implement organizational commitment educational interventions or programs that can positively promote gender role conflict, and job satisfaction, considering for the general characteristics of male nurses.

The present study has limitations as the results may not be generalized to the whole country because samples were taken by convenient sampling of 8 regional hospitals and the sample size was small. Therefore, further studies may need to be conducted by increasing the number of participants nationwide. In addition, studies may need to be conducted on nursing occupational groups where there are relatively more male nurses.

\section{Conflicts of Interest}

The authors have no conflicts of interest to declare.

\section{Funding}

This article was based on a part of the first author's Master's thesis from Eulji University from 2019.

\section{References}

[1] Lee J [Internet]. Open the era of 20,000 male nurses. The Korean Nurses Association News; 2020 [cited 2021 Jan 2]. Available from: http://www. nursenews.co.kr/main/ArticleDetailView.asp?sSection $=61$ \&idx $=24940$.

[2] Lee SS [Dissertation]. The Effects of male nurses of hospital organization culture on the level of job satisfaction-focused on the hospitals around capital areas. Seoul (Korea): Catholic University; 2010.

[3] Shin JH, Seo MH, Lee MI. Nursing jobs and gender in our age of convergence: Research on male nurses. J Digit Converg 2016;14(3):28797.

[4] Kim So, Kang Y. A prediction model on the male nurses' turnover intention. Korean J Adult Nurs 2016;28(5):585-94.

[5] Ahn KH, Seo JM, Hwang SK. Content analysis of male hospital nurses' 
experiences. Korean J Adult Nurs 2009;21(6):652-65.

[6] Seong JS, Yeom EY. The types and characteristics of the male nurses perceived by female nurses: An application of Q-methodology. J Korea Acad Ind Coop Soc 2016;17(1):572-84.

[7] Mowday RT, Steers RM, Porter LW. The measurement of organizational commitment. J Vocat Behav 1979;14(2):224-47.

[8] Buchanan B. Building organizational commitment: The socialization of managers in work organizations. Adm Sci Q 1974:533-46.

[9] Faul F, Erdfelder E, Lang AG, Buchner A. G* Power 3: A flexible statistical power analysis program for the social, behavioral, and biomedical sciences. Behav Res Methods 2007;39(2):175-91.

[10] Kim DI. A study on the relationship between gender stereotypes and authoritarianism. Research Institute of Korean Culture, Ewha Womans University 1993;63(2-3):45-58.

[11] Lee SY, Kim IS, Kim JH, Kim JA. Development of Korean male gender role conflict scale. Women Stud 2012;82(1):5-33.

[12] Weiss DJ, Dawis RV, England GW. Manual for the Minnesota satisfaction questionnaire. Minnesota Stud Vocat Rehabil 1967;22:120.

[13] Park IJ [Dissertation]. A validation study of the Minnesota satisfaction questionnaire (MSQ). Seoul (Korea): Seoul National University; 2005.

[14] Meyer JP, Allen NJ, Smith CA. Commitment to organizations and occupations: Extension and test of a three-component conceptualization. J Appl Psychol 1993;78(4):538-51.

[15] Lee E, Park B. The relationship among gender stereotype, role conflict and organizational commitment of male nurses. Korea J Hosp Manag 2018;23(2):67-81.

[16] Han SH [Dissertation]. The effect of nurses' gender stereotypes on the evaluation of male nurses' nursing performance. Daegu (Korea): Keimyung university; 2017.

[17] Shin CO, Chang SC, Sung JH. Influences of a liberal science class formed integrated gender perspective through exploration of human nature based on evolutionary science on the gender role stereotypes of college students. Korean J Gen Educ 2016;10(3):787-845.
[18] Lee KJ, Kim M. The relationship of gender role conflict and job satisfaction upon organizational commitment in male nurses. Korean J Adult Nurs 2014;26(1):46-57.

[19] Yeom EY, Seo KS. The influence of gender role conflict, nursing professionalism on turnover intention among male nurses. J Korea Contents Assoc 2016;16(12):794-804.

[20] Carvajal MJ, Popovici I. Gender, age, and pharmacists' job satisfaction. Pharm Pract (Granada) 2018;16(4):1396.

[21] O'Lynn CE, O'Connor T, Herakova LL, Kellett P. Men's decision-making to become nurses: gendered influences and fit with gender role conflict theory. ANS Adv Nurs Sci 2020;43(3):251-65.

[22] An ES, Chu SK. Study on male nurses' gender stereotype and job satisfaction. J Korean Acad Nurs Adm 2011;17(1):14-21.

[23] Akbari M, Bagheri A, Fathollahi A, Darvish M. Job satisfaction among nurses in Iran: Does gender matter? J Multidiscip Health 2020;13:71-8.

[24] Lee JS. Effects of nurses' resilience, job satisfaction, and social support on organizational commitment. Korean J Health Serv Manag 2018;12(1):5767.

[25] Oh JJ, Kim JM. The causal relationship among organizational commitment, organizational socialization, job characteristics, and proactive behavior of new employees in large corporations. J Agric Educ Hum Resource Dev 2015;47(3):83-116.

[26] Park GJ, Kim YN. Factors influencing organizational commitment among hospital nurses. J Korean Acad Nurs Adm 2010;16(3):250-8.

[27] Abou Hashish EA. Relationship between ethical work climate and nurses' perception of organizational support, commitment, job satisfaction and turnover intent. Nurs Ethics 2017;24(2):151-66.

[28] Chang CS. Moderating effects of nurses' organizational support on the relationship between job satisfaction and organizational commitment. West J Nurs Res 2015;37(6):724-45.

[29] Ćulibrk J, Delić M, Mitrović S, Ćulibrk D. Job satisfaction, organizational commitment, and job involvement: The mediating role of job involvement. Front Psychol 2018;9:132. 